\title{
Association of ocular diseases with schizophrenia, bipolar disorder, and major depressive disorder: a retrospective case- control, population-based study
}

Chun-Hao Liu' ${ }^{1,2,3,4+}$, Eugene Yu-Chuan Kang ${ }^{3,5+}$, Yu-Hsiang Lin ${ }^{3,6,7}$, Wei-Chi Wü3,5, Zhuo-Hao Liü, Chang-Fu Kuo ${ }^{3,9}$, Chi-Chun Lai ${ }^{3,5}$ and Yih-Shiou Hwang ${ }^{3,5^{*}}$

\begin{abstract}
Background: Psychiatric disorders and ocular neurovascular diseases may share a similar pathophysiological route of vascular structures or neurological changes. The aim of this study is to investigate the association between ocular neurovascular diseases and the risk of major psychiatric disorders.

Methods: This was a retrospective case-control, population-based study including patients aged $\geq 20$ and were diagnosed between 1997 and 2013. Ocular neurovascular diseases diagnosed between 1997 and 2006 and newly diagnosed psychiatric disorders including bipolar disorder (BD), major depressive disorder (MDD), and schizophrenia between 2007 and 2013 were registered. Patients were propensity-score matched with control groups without psychiatric disorders in each cohort based on selected covariates.

Results: A total of one million sampled patients in the database were categorized based on their diagnoses; 2243 (37.4\% men) were categorized into the BD group, 10,110 (35.2\% men) into the MDD group, and 1623 (43.1\% men) into the schizophrenia group. In the BD group, all glaucoma (OR 1.49, [1.18-1.89]), open-angle glaucoma (OR 2.08, [1.34-3.24]), and closed-angle glaucoma (OR 2.12, [1.36-3.33]) showed statistical significance of risk. In the MDD group, age-related macular degeneration (OR 1.33, [1.13-1.57]), all glaucoma (OR 1.24, [1.11-1.37]), open-angle glaucoma (OR 1.47, [1.21-1.80]), and dry eye syndrome (OR 1.22, [1.13-1.31]) were associated with a significantly higher risk. In the schizophrenia group, only all glaucoma (OR 1.47, [1.02-2.11]), glaucoma suspect (OR 1.88, [1.013.49]), and open-angle glaucoma (OR 2.19, [1.13-4.26]) showed statistical significance.
\end{abstract}

Conclusions: In this population-based study, ocular neurovascular diseases, especially glaucoma, were associated with increased risks of $\mathrm{BD}, \mathrm{MDD}$, and schizophrenia.

Keywords: Glaucoma, Ocular neurovascular diseases, Psychiatric disorders, Mental disorders

\footnotetext{
* Correspondence: yihshiou.hwang@gmail.com

${ }^{\dagger}$ Chun-Hao Liu and Eugene Yu-Chuan Kang contributed equally to this work.

${ }^{3}$ College of Medicine, Chang Gung University, Taoyuan, Taiwan

${ }^{5}$ Department of Ophthalmology, Chang Gung Memorial Hospital, Linkou

Medical Center, Taoyuan, Taiwan

Full list of author information is available at the end of the article
}

(c) The Author(s). 2020 Open Access This article is licensed under a Creative Commons Attribution 4.0 International License, which permits use, sharing, adaptation, distribution and reproduction in any medium or format, as long as you give appropriate credit to the original author(s) and the source, provide a link to the Creative Commons licence, and indicate if changes were made. The images or other third party material in this article are included in the article's Creative Commons. licence, unless indicated otherwise in a credit line to the material. If material is not included in the article's Creative Commons licence and your intended use is not permitted by statutory regulation or exceeds the permitted use, you will need to obtain permission directly from the copyright holder. To view a copy of this licence, visit http://creativecommons.org/licenses/by/4.0/ The Creative Commons Public Domain Dedication waiver (http://creativecommons.org/publicdomain/zero/1.0/) applies to the data made available in this article, unless otherwise stated in a credit line to the data. 


\section{Background}

Psychiatric disorders, including schizophrenia, bipolar disorder (BD), and major depressive disorder (MDD), can cause significant global disease burden, disability, and even premature mortality [1, 2]. Although many studies have focused on the pathophysiology of psychiatric disorders, the association between psychiatric disorders and systemic physical conditions is still under investigation. In 2015, a study reported that patients diagnosed with BD or MDD had a tier II moderate risk of cardiovascular disorders in later life [3]. Additionally, BD and MDD were associated with vascular diseases through pathophysiological factors (such as inflammation or endothelial dysfunction), behavioral and environmental factors, and medication-related factors [3, 4].

Microvasculature of the retina is easily observed and shares the same morphological, physiological, and pathological properties as the cerebral vasculature, making the eyes ideal "windows" for evaluating central nervous system disorders [5]. According to previous investigations, retinal vascular change or degeneration was associated with cerebral diseases such as Alzheimer's and Parkinson's disease $[6,7]$. These associations indicate that we can monitor or screen cerebral diseases through certain ocular conditions. Understanding any association between psychiatric disorders and ocular diseases may lead to the discovery that they also share similar pathophysiological routes of vascular structure or neurological changes.

Previous studies have found some significant retinal changes in patients with psychiatric disorders, especially $\mathrm{BD}$ and schizophrenia; both had a higher tortuosity index of retinal arterioles [8] and increased complexity of vascular branching [9]. Another study found that a lower arteriovenular ratio was associated with higher diastolic blood pressure, and a higher arterio-venular ratio was associated with better endothelial function in patients with BD but not in healthy controls [10]. In addition to the microvasculature, the retinal ganglion cell layer also showed some differences in patients with $\mathrm{BD}$ and schizophrenia. The retinal ganglion cell layers were thinner in patients with $\mathrm{BD},[11]$ whereas the retinal nerve fiber and ganglion cell layer were both thinner in patients with $\mathrm{BD}$ and schizophrenia compared with healthy controls [12, 13]. There has only been a limited study on retinal structure abnormalities in patients with MDD.

The association between psychiatric disorders and ocular diseases is still under investigation; only a few studies have focused on this issue, and the majority of them were cross sectional studies that lacked a large sample size. Because these studies were unable to clarify the association between psychiatric disorders and ocular diseases, we conducted a population-based study to investigate the association between psychiatric disorders and ocular diseases by using a longitudinal design.

\section{Methods}

\section{Study population}

This retrospective case-control study examined the association between ophthalmology diseases and psychiatric disorders. This study was conducted based on the Longitudinal Health Insurance Database 2010 (LHID 2010), which is a subset of the database from the Taiwan National Health Insurance Research Database (NHIRD). The LHID 2010 includes data relating to the insurance claims of one million randomly sampled people from 1997 to 2013. The single-payer Taiwan National Health Insurance (NHI) covered most of the medical expenditure, including inpatient and outpatient services in Taiwan. Because of NHI's mandatory enrollment and affordability in Taiwan, long-term follow-up is nearly complete. Further information regarding the NHI program and the NHIRD has been reported in previous publications [14-16]. To ensure patient privacy, all identifiable data were encrypted before release; thus, researchers cannot identify individuals from the data. The study was approved by the Chang Gung Memorial Hospital Institutional Review Board (201900967B0).

\section{Study design}

In this study, we investigated whether exposure to ocular neurovascular disease in a psychiatric disorder-free cohort increases the risk of psychiatric disorder. We established three study cohorts based on three psychiatric disorders: (1) BD, (2) MDD, and (3) schizophrenia. Patients were respectively identified based on their diagnosis of BD, MDD, or schizophrenia, made between January 1, 2007, and December 31, 2013. Cases were ascertained through three or more diagnoses by a psychiatrist during outpatient visits. The date of the first diagnosis of BD, MDD, or schizophrenia was the index date for the case group. The control group included patients without any diagnosis of $\mathrm{BD}, \mathrm{MDD}$, or schizophrenia during the period of our database (1997 to 2013), respectively, in each cohort. The index date of the control group was assigned from that of their counterpart case group. Patients with BD, MDD, or schizophrenia diagnosed between 1997 and 2006; aged less than 20 years; or with a history of substance use or alcoholism were excluded (Fig. 1). Finally, patients who had received a new diagnosis of psychiatric disorders were propensity-score matched with control patients based on selected covariates.

\section{Exposure to ocular disease and covariates}

Within the three cohorts, we recorded ocular neurovascular diseases, including age-related macular degeneration, central serous retinopathy, retinal vascular 


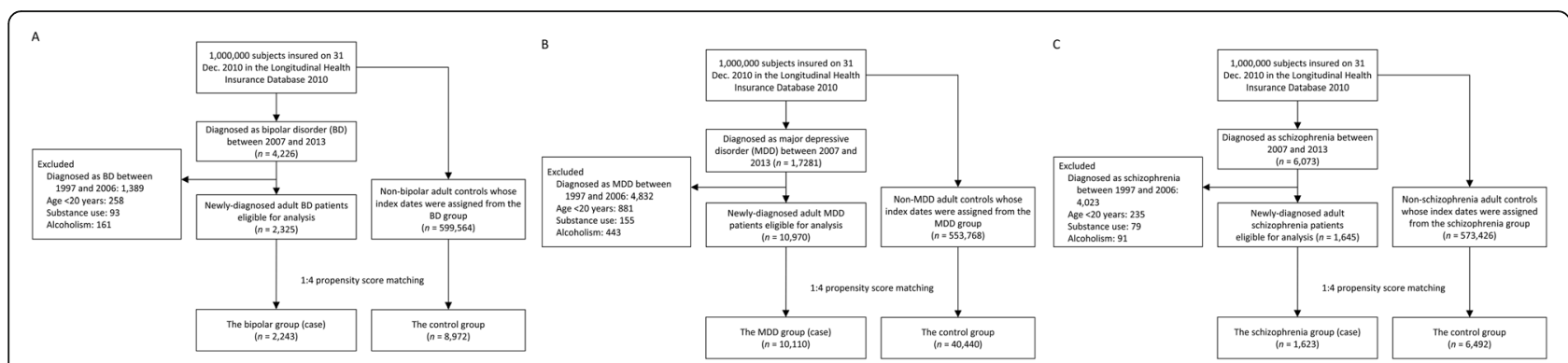

Fig. 1 a Flow chart of subject selection of bipolar disorder (BD) from the NHIRD. b Flow chart of subject selection of major depressive disorder (MDD) from the NHIRD. c Flow chart of subject selection of schizophrenia from the NHIRD

occlusion, diabetic retinopathy, glaucoma, dry eye syndrome, and optic neuritis, diagnosed between January 1, 1997, and December 31, 2006. To detect the possibility of unmeasured confounding factors, we also identified several negative control exposures to ocular diseases, including retinal detachment, uveitis, and blepharitis [17]. Exposure was ascertained through three or more diagnoses by an ophthalmologist during outpatient visits, and all exposures to ocular disease were censored and counted for the analysis. The covariates included age at the index date, sex, urbanization level, monthly income, comorbidities (anxiety disorder, hypertension, dyslipidemia, diabetes, coronary heart disease, chronic obstructive pulmonary disease, chronic kidney disease, and stroke), and the Charlson Comorbidity Index (CCI) score. Comorbidity was considered based on a minimum of three outpatient diagnoses or one inpatient diagnosis performed between 1997 and the index date. Comorbidities were identified using the International Classification of Diseases, Ninth Revision, Clinical Modification (ICD-9-CM) codes, including outcomes, exposure to ocular disease, and comorbidities (Supplementary Table 1).

\section{Statistical analysis}

To reduce possible confounding factors caused by selection bias, a propensity score matching (PSM) method was used in this study. The propensity score was the predicted probability to be in the case group given the values of covariates and using multivariable logistic regression without considering interaction effects. The variables selected to calculate the propensity score were baseline characteristics (Table 1). Each patient in the case group was matched with four control patients. The matching was processed using a greedy nearest neighbor algorithm with a caliper of 0.2 times the standard deviation of the logit of the propensity score, with random matching order and without replacement. Three separate PSMs were conducted for each of the three psychiatric disorders. The quality of matching was checked using the absolute value of the standardized difference (STD) between the groups, where a value less than 0.1 was considered a negligible difference. The association of each ocular disease and psychiatric disorder was investigated using the generalized estimating equation (GEE), in which the within-pair clustering of outcomes after PSM was accounted for by using a robust standard error and exchangeable working correlation. The link function was logit, and the distribution was binomial in the GEE model. A two-sided $P$ value of $<.05$ was considered statistically significant, and no adjustment for multiple testing (multiplicity) was made in this study. All statistical analyses were performed using SAS version 9.4 (SAS Institute, Cary, $\mathrm{NC}$ ), including the procedures of "psmatch" for PSM and "genmod" for GEE.

\section{Results}

\section{Study cohorts and characteristics}

Among one million patients in the LHID 2010, between 2007 and 2013, a total of 4226 patients were diagnosed with BD, 17281 were diagnosed with MDD, and 6073 were diagnosed with schizophrenia. After applying excluding criteria, there were 2325 newly diagnosed BD cases; 10,970 newly diagnosed MDD cases, and 1645 newly diagnosed patients with schizophrenia eligible for analysis. After PSM, 2243 cases and 8972 controls, 10, 110 cases and 40,440 controls, and 1623 cases and 6492 controls remained for the $\mathrm{BD}, \mathrm{MDD}$, and schizophrenia cohorts, respectively (Fig. 1). After PSM, the mean age of cases was $43.5 \pm 16.1$ years for the BD cohort, $47.7 \pm$ 16.9 years for the MDD cohort, and $41.9 \pm 14.3$ years for the schizophrenia cohort. All the characteristics were well-balanced between the case and control groups in the 3 study cohorts (Table 1).

\section{Bipolar disorder cohort}

The result of the GEE model showed that previous glaucoma was associated with a higher risk of BD (OR 1.49, 95\% CI 1.18-1.89). Among the different types of glaucoma, glaucoma suspect (OR 1.63, 95\% CI 1.09-2.43), 
Table 1 Characteristics of cases after propensity score matching

\begin{tabular}{|c|c|c|c|c|c|c|c|c|c|}
\hline \multirow[b]{2}{*}{ Variable } & \multicolumn{3}{|c|}{ Bipolar Disorder } & \multicolumn{3}{|c|}{ Major Depressive Disorder } & \multicolumn{3}{|l|}{ Schizophrenia } \\
\hline & $\begin{array}{l}\mathrm{BD} \\
(n=2243)\end{array}$ & $\begin{array}{l}\text { Control } \\
(n=8972)\end{array}$ & STD & $\begin{array}{l}\text { MDD } \\
(n=10,110)\end{array}$ & $\begin{array}{l}\text { Control } \\
(n=40,440)\end{array}$ & STD & $\begin{array}{l}\text { Schizophrenia } \\
(n=1623)\end{array}$ & $\begin{array}{l}\text { Control } \\
(n=6492)\end{array}$ & STD \\
\hline Male & $838(37.4)$ & $3311(36.9)$ & 0.01 & $3561(35.2)$ & $14,126(34.9)$ & 0.01 & $699(43.1)$ & $2753(42.4)$ & 0.01 \\
\hline Age (years) & $43.5 \pm 16.1$ & $43.3 \pm 15.9$ & 0.01 & $47.7 \pm 16.9$ & $47.3 \pm 17.3$ & 0.03 & $41.9 \pm 14.3$ & $42.3 \pm 14.5$ & -0.03 \\
\hline \multicolumn{10}{|l|}{ Urbanization level } \\
\hline Low & $152(6.8)$ & $583(6.5)$ & 0.01 & $781(7.7)$ & $3137(7.8)$ & $<0.01$ & $174(10.7)$ & $665(10.2)$ & 0.02 \\
\hline Moderate & $584(26.0)$ & $2384(26.6)$ & -0.01 & $2787(27.6)$ & $11,135(27.5)$ & $<0.01$ & $474(29.2)$ & $1926(29.7)$ & -0.01 \\
\hline High & $768(34.2)$ & 3034 (33.8) & 0.01 & $3373(33.4)$ & $13,564(33.5)$ & $<0.01$ & $494(30.4)$ & $1969(30.3)$ & $<0.01$ \\
\hline Very High & 739 (32.9) & $2971(33.1)$ & $<0.01$ & 3169 (31.3) & $12,604(31.2)$ & $<0.01$ & $481(29.6)$ & $1932(29.8)$ & $<0.01$ \\
\hline \multicolumn{10}{|l|}{ Monthly income, NTD } \\
\hline $0-17,880$ & $886(39.5)$ & $3553(39.6)$ & $<0.01$ & 3419 (33.8) & $13,798(34.1)$ & -0.01 & $920(56.7)$ & $3673(56.6)$ & $<0.01$ \\
\hline $17,881-22,800$ & $757(33.7)$ & $3051(34.0)$ & -0.01 & $3373(33.4)$ & $13,499(33.4)$ & $<0.01$ & $485(29.9)$ & 2035 (31.3) & -0.03 \\
\hline$>22,800$ & $600(26.7)$ & $2368(26.4)$ & 0.01 & $3318(32.8)$ & $13,143(32.5)$ & 0.01 & $218(13.4)$ & $784(12.1)$ & 0.04 \\
\hline \multicolumn{10}{|l|}{ Comorbidity } \\
\hline Anxiety disorder & $1399(62.4)$ & $5553(61.9)$ & 0.01 & $5307(52.5)$ & $21,312(52.7)$ & $<0.01$ & $655(40.4)$ & $2626(40.4)$ & $<0.01$ \\
\hline Hypertension & $521(23.2)$ & $1976(22.0)$ & 0.03 & 2918 (28.9) & $11,390(28.2)$ & 0.02 & $263(16.2)$ & $1057(16.3)$ & $<0.01$ \\
\hline Dyslipidemia & $409(18.2)$ & $1532(17.1)$ & 0.03 & $2252(22.3)$ & $8766(21.7)$ & 0.01 & $179(11.0)$ & $715(11.0)$ & $<0.01$ \\
\hline Diabetes & $268(11.9)$ & $1040(11.6)$ & 0.01 & $1351(13.4)$ & $5213(12.9)$ & 0.01 & $136(8.4)$ & $552(8.5)$ & $<0.01$ \\
\hline Coronary heart disease & $262(11.7)$ & $973(10.8)$ & 0.03 & 1649 (16.3) & $6283(15.5)$ & 0.02 & $112(6.9)$ & $481(7.4)$ & -0.02 \\
\hline COPD & $203(9.1)$ & $781(8.7)$ & 0.01 & $1115(11.0)$ & $4391(10.9)$ & 0.01 & $113(7.0)$ & $459(7.1)$ & $<0.01$ \\
\hline Chronic kidney disease & $151(6.7)$ & $593(6.6)$ & $<0.01$ & $815(8.1)$ & $3145(7.8)$ & 0.01 & $80(4.9)$ & $345(5.3)$ & -0.02 \\
\hline Stroke & $71(3.2)$ & $267(3.0)$ & 0.01 & $441(4.4)$ & $1643(4.1)$ & 0.01 & $47(2.9)$ & $187(2.9)$ & $<0.01$ \\
\hline CCl score & $0.56 \pm 1.13$ & $0.55 \pm 1.21$ & 0.01 & $0.68 \pm 1.24$ & $0.62 \pm 1.23$ & 0.05 & $0.39 \pm 0.96$ & $0.38 \pm 1.01$ & 0.01 \\
\hline
\end{tabular}

$B D$ bipolar disorder; $M D D$ major depressive disorder; STD standardized difference; OPD outpatient clinic; OPH ophthalmology; NTD new Taiwan dollar; COPD chronic obstructive pulmonary disease; $\mathrm{CCl}$ Charlson Comorbidity Index; Data are presented as the frequency (percentage) or the mean \pm standard deviation

open-angle glaucoma (OR 2.08, 95\% CI 1.34-3.24), closed-angle glaucoma (OR 2.12, 95\% CI 1.36-3.33), and undetermined glaucoma (OR 1.46, 95\% CI 1.04-2.04) showed significant associations with BD. In addition, there were no associations between the negative control ocular diseases and risk of BD (Table 2).

\section{Major depressive disorder cohort}

Among the ophthalmologic diseases, the GEE model showed that age-related macular degeneration (OR 1.33, 95\% CI 1.13-1.57), glaucoma (OR 1.24, 95\% CI $1.11-1.37$ ), and dry eye syndrome (OR 1.22, 95\% CI 1.13-1.31) were significantly associated with a higher risk of MDD. Among the different types of glaucoma, glaucoma suspect (OR 1.47, 95\% CI 1.22-1.76), openangle glaucoma (OR 1.47, 95\% CI 1.21-1.80), and undetermined glaucoma (OR 1.21, 95\% CI 1.05-1.40) were significantly associated with MDD. With respect to the negative control diseases, blepharitis was associated with a lower risk of MDD (OR 0.87, 95\% CI 0.77-0.98; Table 3).

\section{Schizophrenia cohort}

The results demonstrated that a presence of previous glaucoma was significantly associated with a higher risk of schizophrenia (OR 1.47, 95\% CI 1.02-2.11). Among the different types of glaucoma, glaucoma suspect (OR $1.88,95 \%$ CI 1.01-3.49) and open-angle glaucoma (OR 2.19, 95\% CI 1.13-4.26) showed significant associations with schizophrenia. However, no significant associations were observed between other ocular neurovascular diseases or negative control and schizophrenia (Table 4).

\section{Discussion}

In our study, we found that ocular neurovascular diseases were associated with psychiatric disorders. Glaucoma had the strongest association in all BD, MDD, and schizophrenia cohorts. Additionally, age-related macular degeneration and dry eye syndrome were associated with MDD.

Glaucoma was once considered to be a disease related to elevated intraocular pressure but is now viewed as a neurodegenerative disease [18]. It was also associated with ocular perfusion pressure and vascular dysfunction 
Table 2 Association between each ocular disease and the risk of bipolar disorder (BD)

\begin{tabular}{|c|c|c|c|c|}
\hline \multirow[b]{2}{*}{ Ocular Disease } & \multicolumn{2}{|c|}{ Number (\%) } & \multicolumn{2}{|l|}{ Risk of BD } \\
\hline & $\begin{array}{l}\text { BD } \\
(n=2243)\end{array}$ & $\begin{array}{l}\text { Control } \\
(n=8972)\end{array}$ & OR (95\% Cl) & $P$ \\
\hline Age-related macular degeneration & $29(1.29)$ & $95(1.06)$ & $1.22(0.80-1.86)$ & 0.347 \\
\hline Central serous retinopathy & $3(0.13)$ & $23(0.26)$ & $0.52(0.16-1.74)$ & 0.289 \\
\hline Retinal vascular occlusion & $4(0.18)$ & $23(0.26)$ & $0.70(0.24-2.01)$ & 0.503 \\
\hline Diabetic retinopathy & $37(1.65)$ & $168(1.87)$ & $0.88(0.61-1.26)$ & 0.481 \\
\hline Glaucoma & $93(4.15)$ & $253(2.82)$ & $1.49(1.18-1.89)$ & 0.001 \\
\hline Glaucoma suspect & $34(1.52)$ & $84(0.94)$ & $1.63(1.09-2.43)$ & 0.017 \\
\hline Open-angle glaucoma & $30(1.34)$ & $58(0.65)$ & $2.08(1.34-3.24)$ & 0.001 \\
\hline Closed-angle glaucoma & $29(1.29)$ & $55(0.61)$ & $2.12(1.36-3.33)$ & 0.001 \\
\hline Undetermined glaucoma & $46(2.1)$ & $127(1.4)$ & $1.46(1.04-2.04)$ & 0.027 \\
\hline Dry eye syndrome & $184(8.20)$ & $687(7.66)$ & $1.08(0.91-1.27)$ & 0.380 \\
\hline Optic neuropathy & $1(0.04)$ & $11(0.12)$ & $0.36(0.05-2.82)$ & 0.333 \\
\hline \multicolumn{5}{|l|}{ Negative control exposure } \\
\hline Retinal detachment & $5(0.22)$ & $28(0.31)$ & $0.71(0.27-1.85)$ & 0.488 \\
\hline Uveitis & $15(0.67)$ & $67(0.75)$ & $0.89(0.51-1.56)$ & 0.696 \\
\hline Blepharitis & $70(3.12)$ & $303(3.38)$ & $0.92(0.71-1.20)$ & 0.538 \\
\hline
\end{tabular}

$O R$ odds ratio; $\mathrm{Cl}$ confidence interval; $N A$ not applicable

[19]. A previous study reported that glaucoma was associated with anxiety, depression, and sleep disturbance, and the severity of glaucoma was a predictor of psychiatric disorder [20]. Another large-scale population-based study showed a significant association between glaucoma and anxiety/depression [21]. However, most of those studies consisted of a cross-sectional design and failed to clarify temporality. A previous retrospective study found that veterans with severe mental illness (schizophrenia, schizoaffective disorder, BD, and other psychosis) had an elevated risk of ocular diseases, including cataracts and glaucoma [22]. However, the study did not discuss the

Table 3 Association between each ocular disease and the risk of major depressive disorder (MDD)

\begin{tabular}{|c|c|c|c|c|}
\hline \multirow[b]{2}{*}{ Ocular Disease } & \multicolumn{2}{|l|}{ Number (\%) } & \multicolumn{2}{|l|}{ Risk of MDD } \\
\hline & $\begin{array}{l}\text { MDD } \\
(n=10,110)\end{array}$ & $\begin{array}{l}\text { Control } \\
(n=40,440)\end{array}$ & OR $(95 \% \mathrm{Cl})$ & $P$ \\
\hline Age-related macular degeneration & $195(1.93)$ & $589(1.46)$ & $1.33(1.13-1.57)$ & 0.001 \\
\hline Central serous retinopathy & $25(0.25)$ & $78(0.19)$ & $1.28(0.82-2.01)$ & 0.280 \\
\hline Retinal vascular occlusion & $37(0.37)$ & $122(0.30)$ & $1.21(0.84-1.76)$ & 0.304 \\
\hline Diabetic retinopathy & $230(2.27)$ & $972(2.40)$ & $0.95(0.82-1.09)$ & 0.447 \\
\hline Glaucoma & $460(4.55)$ & $1501(3.71)$ & $1.24(1.11-1.37)$ & $<0.001$ \\
\hline Glaucoma suspect & $161(1.59)$ & $441(1.09)$ & $1.47(1.22-1.76)$ & $<0.001$ \\
\hline Open-angle glaucoma & $138(1.36)$ & $376(0.93)$ & $1.47(1.21-1.80)$ & $<0.001$ \\
\hline Closed-angle glaucoma & $130(1.29)$ & $433(1.07)$ & $1.20(0.99-1.47)$ & 0.067 \\
\hline Undetermined glaucoma & $235(2.3)$ & $777(1.9)$ & $1.21(1.05-1.40)$ & 0.009 \\
\hline Dry eye syndrome & $994(9.83)$ & $3326(8.22)$ & $1.22(1.13-1.31)$ & $<0.001$ \\
\hline Optic neuropathy & $14(0.14)$ & $42(0.10)$ & $1.33(0.73-2.44)$ & 0.351 \\
\hline \multicolumn{5}{|l|}{ Negative control exposure } \\
\hline Retinal detachment & $35(0.35)$ & $129(0.32)$ & $1.09(0.75-1.58)$ & 0.668 \\
\hline Uveitis & $100(0.99)$ & $338(0.84)$ & $1.19(0.95-1.48)$ & 0.138 \\
\hline Blepharitis & $336(3.32)$ & 1545 (3.82) & $0.87(0.77-0.98)$ & 0.019 \\
\hline
\end{tabular}


Table 4 Association between each ocular disease and the risk of schizophrenia

\begin{tabular}{|c|c|c|c|c|}
\hline \multirow[b]{2}{*}{ Ocular Disease } & \multicolumn{2}{|l|}{ Number (\%) } & \multicolumn{2}{|c|}{ Risk of schizophrenia } \\
\hline & $\begin{array}{l}\text { Schizophrenia } \\
(n=1623)\end{array}$ & $\begin{array}{l}\text { Control } \\
(n=6492)\end{array}$ & OR $(95 \% \mathrm{Cl})$ & $P$ \\
\hline Age-related macular degeneration & $10(0.62)$ & $36(0.55)$ & $1.11(0.55-2.25)$ & 0.768 \\
\hline Central serous retinopathy & $0(0.0)$ & $8(0.12)$ & NA & NA \\
\hline Retinal vascular occlusion & $0(0.0)$ & $13(0.20)$ & NA & NA \\
\hline Diabetic retinopathy & $14(0.86)$ & $71(1.09)$ & $0.79(0.44-1.40)$ & 0.418 \\
\hline Glaucoma & $39(2.40)$ & $107(1.65)$ & $1.47(1.02-2.11)$ & 0.037 \\
\hline Glaucoma suspect & $15(0.92)$ & $32(0.49)$ & $1.88(1.01-3.49)$ & 0.045 \\
\hline Open-angle glaucoma & $12(0.74)$ & $22(0.34)$ & $2.19(1.13-4.26)$ & 0.021 \\
\hline Closed-angle glaucoma & $6(0.37)$ & $29(0.45)$ & $0.83(0.34-2.00)$ & 0.673 \\
\hline Undetermined glaucoma & $19(1.2)$ & $46(0.7)$ & $1.66(0.98-2.81)$ & 0.059 \\
\hline Dry eye syndrome & $78(4.81)$ & $295(4.54)$ & $1.06(0.82-1.37)$ & 0.655 \\
\hline Optic neuropathy & $0(0.0)$ & $3(0.05)$ & NA & NA \\
\hline \multicolumn{5}{|l|}{ Negative control exposure } \\
\hline Retinal detachment & $2(0.12)$ & $13(0.20)$ & $0.61(0.14-2.73)$ & 0.523 \\
\hline Uveitis & $5(0.31)$ & $23(0.35)$ & $0.87(0.33-2.29)$ & 0.777 \\
\hline Blepharitis & $26(1.60)$ & $137(2.11)$ & $0.76(0.50-1.15)$ & 0.188 \\
\hline
\end{tabular}

$O R$ odds ratio; $\mathrm{Cl}$ confidence interval, $N A$ not applicable

pattern of different ocular diseases in each mental illness.

In the present study, we found associations between glaucoma and BD, MDD, and schizophrenia. Among the different types of glaucoma, glaucoma suspect and openangle glaucoma were associated with all the three target psychiatric disorders. Closed-angle glaucoma was associated with BD and positively correlated with MDD but without statistical significance. Undetermined glaucoma was associated with $\mathrm{BD}$ and MDD and also positively correlated with schizophrenia, although this was not statistically significant. Other than glaucoma, age-related macular degeneration and dry eye syndrome were associated with MDD, but this trend was not observed in the $\mathrm{BD}$ and schizophrenia groups.

Loss of vision, social, and daily life function has been reported to be associated with increased risk of MDD in glaucoma [23, 24]. In our study, we analyzed additional ocular disorders with potential loss of vision and social function in addition to glaucoma. For example, retinal vascular occlusion is associated with severe vision loss and visual field defect [25]; diabetic retinopathy is among the leading causes of legal blindness in workingage adults and the leading cause of vision-threatening retinopathy [26, 27]. In non-neurovascular exposures, the visual outcome of retinal detachment is uncertain, and surgical interventions for retinal detachment (with attendant postoperative complications) are usually required [28, 29]; uveitis, which causes several visionthreatening complications such as macular edema and cataract, was reported to account for up to $10 \%$ of legal blindness in the United States [30, 31]. For these ocular disorders, however, we did not find a significant association with MDD. Thus, psychosocial factors or vision loss may not explain the association between glaucoma and psychiatric disorders identified in our study.

Neurodegenerative process may support the association between glaucoma and psychiatric disorders. One previous study has found that BD and MDD were associated with neurological deficits [3]. Furthermore, glaucoma is characterized by progressive optic nerve degeneration [32] and was recently considered to be a neurodegenerative disease [33]. It has been suggested that the link between mental disorders and glaucoma is attributed to their similar disease pathophysiology. Although the pathogenesis of glaucoma is related to retinal ganglion cell death, caused by intraocular pressure, different types of glaucoma have a slightly different pathophysiology [34]. For example, closed-angle glaucoma is related to ocular structural abnormalities, which leads to elevated intraocular pressure, whereas open-angle glaucoma is more likely to occur in primary neural pathological processes [34]. This may indicate a stronger association between open-angle glaucoma and metal disorders found in our study. As for glaucoma suspect, it is dependent on a normal open angle upon ocular examination and is sometimes defined as an early open-angle glaucoma. In addition to the neurodegenerative hypothesis, glaucoma treatment and its chronic asymptomatic, but potentially blinding nature, may also increase the risk of MDD [21, 35-37]. 
Regarding dry eye syndrome and age-related macular degeneration, which were both shown to be associated with MDD, there is supporting evidence to our findings. The connection between dry eye syndrome and affective disorders, especially anxiety and MDD, has been discussed [38]. Although the cause and effect relationship remains unknown, similar etiopathogenic and neuropathogenic mechanisms were suggested [38]. As for agerelated macular degeneration, it is a potentially distressing medical condition because of the vision loss, financial burden of treatment, and long-term need of intraocular injection [39]. Although the association between age-related macular degeneration and MDD at the neurological level has not been confirmed, one previous study has indicated a possible physiological connection between the diseases [40].

We chose three common ocular diseases, other than neurovascular disease, as our negative controls for exposure, which included retinal detachment, uveitis, and blepharitis. None of the three diseases showed any significant association with any psychiatric disorders, except blepharitis in MDD. Unlike dry eye syndrome or other ocular neurovascular diseases, blepharitis showed a negative association with MDD. As with MDD, blepharitis has been confirmed to be a risk factor for dry eye syndrome and could accelerate the development of the syndrome [38]. In addition, blepharitis has been suggested to be an early form and manifestation of dry eye syndrome [41]. We hypothesize that patients with MDD and blepharitis, both being risk factors for dry eye syndrome, experience early development of dry eye syndrome. Patients may be diagnosed as having and be treated more predominantly for dry eye syndrome than blepharitis in ophthalmology clinics. This may result in a relatively lower prevalence of blepharitis among MDD group compared with its control group.

To the best of our knowledge, this is the first population-based study with long-term follow-ups to test the association between ocular neurovascular diseases and psychiatric disorders. We not only demonstrated the association but also revealed the temporality between the two groups of diseases. We used a large nationwide, population-based sample as our study population and tried to minimize recall bias and selection bias.

There are still some limitations to this study. First, we identified our study groups based on the ICD codes. We attempted to validate the diagnosis by using three similar diagnoses within our study period, which were made by experts (ophthalmologists or psychiatrists). Without a chart review, we were missing each patient's raw data or other clinical manifestation. Second, psychiatric disorders result from the interactions of bio-psycho-social factors. Our study focused on the biological aspect but cannot evaluate psycho-social confounders between ocular diseases and psychiatric disorders. Third, because the study period included the transition from the ICD-9 and ICD-10 coding system in the Taiwan NHI, we included both ICD-9 and ICD-10 diagnoses, despite the two systems were not perfectly matched for each diagnosis. Fourth, we suggest that patients do not use psychotropic medication before the diagnosis of a psychiatric disorder to rule out the effect of psychotropic medication on the eye; however, in very rare circumstances, they may still use psychotropic medication for other purposes. Finally, we cannot rule out patients who were diagnosed with a psychiatric disorder before our study period but then returned to the NHI system after a long time period without treatment or follow-up. An additional limitation of our study is that patients with prodromal schizophrenia or with untreated psychosis were not be enrolled because the study was based on data collected from a health insurance database. Moreover, the onset of psychiatric disorders, especially schizophrenia, is typically during adolescence or early adulthood. The mean age of our cohort was in the 40 s, which means the study enrolled mostly late onset schizophrenia and excluded early onset cases, and thus, the study population cannot represent all the cases of psychiatric disorders. We examined the demographic data of both excluded and included samples of each major psychiatric disorder group and identified no significant difference between the two (Supplementary Table 2). The most common comorbid ocular neurovascular disease among the excluded samples was glaucoma in all groups (BD, MDD, and schizophrenia) (3.02, 4.08, and $1.96 \%$, respectively; Supplementary Table 3).

\section{Conclusions}

Under the hypothesis of the shared pathophysiology of neurovascular dysfunction, our study established the temporality and association between ocular neurovascular diseases and certain psychiatric diseases. Glaucoma, among other ocular neurovascular diseases, had the most significant association of an increased risk for BD, MDD, and schizophrenia. Among the different types of glaucoma, open-angle glaucoma was associated with all three psychiatric disorders, but closed-angle glaucoma was only associated with an increased risk of BD. Additionally, age-related macular degeneration and dry eye syndrome was associated with an increased risk of MDD. Based on the results, we suggest raising awareness of psychiatric disorder during ophthalmology follow-up for glaucoma and of ocular problems during psychiatry follow-up. Appropriate early screening or consultation with another specialty may be indicated. The actual pathophysiology between glaucoma and psychiatric disorder need further investigation. Knowing more about the pathophysiology, may contribute to more knowledge about the mechanism of psychiatric disorder. 


\section{Supplementary information}

Supplementary information accompanies this paper at https://doi.org/10. 1186/s12888-020-02881-W.

Additional file 1: Supplementary Table 1. ICD-9 CM diagnostic codes used in this study.

Additional file 2: Supplementary Table 2. Characteristics of cases according to exclude or not.Supplementary Table 3. Ocular disease according to bipolar disorder (BD), major depressive disorder (MDD) and schizophrenia.

\section{Abbreviations}

BD: Bipolar disorder; CCl: Charlson Comorbidity Index; GEE: Generalized estimating eq.; ICD-9-CM: International Classification of Diseases, Ninth Revision, Clinical Modification; LHID 2010: Longitudinal Health Insurance Database 2010; MDD: Major depressive disorder; NHIRD: National Health Insurance Research Database; NHI: National Health Insurance;

PSM: Propensity score matching; STD: Standardized difference

\section{Acknowledgements}

None.

\section{Authors' contributions}

Dr. YSH has full access to the data and takes overall responsibility. Conception and design: CHL, YCK, YSH; Data collection and collation: YHL, ZHL; Data analysis and interpretation: WCW, CCL, CFK; Writing: CHL, YCK. All authors read and approved the final manuscript.

\section{Funding}

The study was supported by Chang Gung Memorial Hospital, Taoyuan, Taiwan (CMRPG3C0171, CMRPG3B0441, CORPG3C0081) and National Science Council Research Grants, Taipei, Taiwan (MOST 105-2314-B-182A-076, MOST 106-2314-B-182A-045 -MY3). The funding organization had no role in the design and conduct of this study, including data collection, analysis, interpretation of the data, approval of the manuscript, or decision to submit the work for publication.

\section{Availability of data and materials}

The datasets generated and/or analysed during the current study are not publicly available due legal restriction but are available from the corresponding author on reasonable request.

\section{Ethics approval and consent to participate}

The study was approved by the Chang Gung Memorial Hospital Institutional Review Board (201900967B0). Consent to participate is not applicable

\section{Consent for publication}

Not applicable.

\section{Competing interests}

The authors declare that they have no competing interests.

\footnotetext{
Author details

'Department of Psychiatry, Chang Gung Memorial Hospital, Linkou Medical Center, Taoyuan, Taiwan. ${ }^{2}$ Department of Psychiatry, New Taipei Municipal Tu-Cheng Hospital, New Taipei, Taiwan. ${ }^{3}$ College of Medicine, Chang Gung University, Taoyuan, Taiwan. ${ }^{4}$ Department of Sinophone Literatures, National Dong Hwa University, Hualien, Taiwan. ${ }^{5}$ Department of Ophthalmology, Chang Gung Memorial Hospital, Linkou Medical Center, Taoyuan, Taiwan. ${ }^{6}$ Department of Urology, Chang Gung Memorial Hospital, Linkou Medical Center, Taoyuan, Taiwan. ${ }^{7}$ Graduate Institute of Clinical Medical Sciences, College of Medicine, Chang Gung University, Taoyuan, Taiwan. ${ }^{8}$ Department of Neurosurgery, Chang Gung Memorial Hospital, Linkou Medical Center, Taoyuan, Taiwan. ${ }^{9}$ Department of Rheumatology, Chang Gung Memorial Hospital, Linkou Medical Center, Taoyuan, Taiwan.
}

Received: 22 June 2020 Accepted: 19 September 2020

Published online: 02 October 2020

\section{References}

1. Whiteford HA, Degenhardt L, Rehm J, Baxter AJ, Ferrari AJ, Erskine HE, et al. Global burden of disease attributable to mental and substance use disorders: findings from the global burden of disease study 2010. Lancet. 2013;382(9904):1575-86.

2. Walker ER, McGee RE, Druss BG. Mortality in mental disorders and global disease burden implications: a systematic review and meta-analysis. JAMA Psychiatry. 2015;72(4):334-41.

3. Goldstein BI, Carnethon MR, Matthews KA, Mclntyre RS, Miller GE, Raghuvee $\mathrm{G}$, et al. Major depressive disorder and bipolar disorder predispose youth to accelerated atherosclerosis and early cardiovascular disease: a scientific statement from the American Heart Association. Circulation. 2015;132(10): 965-86.

4. Goldstein BI. Bipolar disorder and the vascular system: mechanisms and new prevention opportunities. Can J Cardiol. 2017;33(12):1565-76.

5. London A, Benhar I, Schwartz M. The retina as a window to the brain-from eye research to CNS disorders. Nat Rev Neurol. 2013;9(1):44-53.

6. Shariflou S, Georgevsky D, Mansour H, Rezaeian M, Hosseini N, Gani F, et al. Diagnostic and prognostic potential of retinal biomarkers in early on-set Alzheimer's disease. Curr Alzheimer Res. 2017;14(9):1000-7.

7. Choi S, Jahng WJ, Park SM, Jee D. Association of age-Related Macular Degeneration on Alzheimer or Parkinson disease: a retrospective cohort study. Am J Ophthalmol. 2020;210:41-7.

8. Appaji A, Nagendra B, Chako DM, Padmanabha A, Jacob A, Hiremath CV, et al. Retinal vascular tortuosity in schizophrenia and bipolar disorder Schizophr Res. 2019;212:26-32.

9. Appaji A, Nagendra B, Chako DM, Padmanabha A, Hiremath CV, Jacob A, et al. Retinal vascular fractal dimension in bipolar disorder and schizophrenia. J Affect Disord. 2019;259:98-103.

10. Naiberg MR, Hatch JK, Selkirk B, Fiksenbaum L, Yang V, Black S, et al. Retinal photography: a window into the cardiovascular-brain link in adolescent bipolar disorder. J Affect Disord. 2017;218:227-37.

11. Kalenderoglu A, Sevgi-Karadag A, Celik M, Egilmez OB, Han-Almis B, Ozen ME. Can the retinal ganglion cell layer (GCL) volume be a new marker to detect neurodegeneration in bipolar disorder? Compr Psychiatry. 2016;67: $66-72$.

12. Khalil DH, Said MM, Abdelraouf MA. Peripapillary retinal nerve fiber layer and ganglion cell complex degeneration in Egyptian patients with bipolar disorder. Eye (London, England). 2019;33(12):1852-8.

13. Lizano P, Bannai D, Lutz O, Kim LA, Miller J, Keshavan M. A meta-analysis of retinal Cytoarchitectural abnormalities in schizophrenia and bipolar disorder. Schizophr Bull. 2019;4;46(1):43-53

14. Hsing AW, loannidis JP. Nationwide population science: lessons from the Taiwan National Health Insurance Research Database. JAMA Intern Med. 2015:175(9):1527-9.

15. Lin LY, Warren-Gash C, Smeeth L, Chen PC. Data resource profile: the National Health Insurance Research Database (NHIRD). Epidemiol Health. 2018:40:e2018062

16. Hsieh CY, Su CC, Shao SC, Sung SF, Lin SJ, Kao Yang YH, et al. Taiwan's National Health Insurance Research Database: past and future. Clin Epidemiol. 2019;11:349-58

17. Lipsitch M, Tchetgen Tchetgen E, Cohen T. Negative controls: a tool for detecting confounding and bias in observational studies. Epidemiology (Cambridge, Mass). 2010;21(3):383-8.

18. Chang EE, Goldberg JL. Glaucoma 2.0: Neuroprotection, Neuroregeneration, Neuroenhancement. Ophthalmology. 2012;119(5):979-86.

19. Cherecheanu AP, Garhofer G, Schmidl D, Werkmeister R, Schmetterer L. Ocular perfusion pressure and ocular blood flow in glaucoma. Cur Opin Pharmacol. 2013;13(1):36-42.

20. Agorastos A, Skevas C, Matthaei M, Otte C, Klemm M, Richard G, et al. Depression, anxiety, and disturbed sleep in glaucoma. J Neuropsychiatry Clin Neurosci. 2013;25(3):205-13.

21. Zhang $X$, Olson DJ, Le P, Lin F-C, Fleischman D, Davis RM. The association between Glaucoma, anxiety, and depression in a large population. Am J Ophthalmol. 2017:183:37-41.

22. Saeedi O, Ashraf H, Malouf M, Slade EP, Medoff DR, Li L, et al. Prevalence of diagnosed ocular disease in veterans with serious mental illness. Gen Hosp Psychiatry. 2016:43:1-5. 
23. Wang SY, Singh K, Lin SC. Prevalence and predictors of depression among participants with Glaucoma in a nationally representative population sample. Am J Ophthamol. 2012;154(3):436-44.

24. Jampel HD, Frick KD, Janz NK, Wren PA, Musch DC, Rimal R, Lichter PR, et al. Depression and mood indicators in newly diagnosed Glaucoma patients. Am J Ophthamol. 2007;144(2):238-44.

25. Hayreh SS. Ocular vascular occlusive disorders: natural history of visual outcome. Prog Retin Eye Res. 2014;41:1-25.

26. Antonetti DA, Klein R, Gardner TW. Diabetic retinopathy. N Engl J Med. 2012;366(13):1227-39.

27. Cheung N, Mitchell P, Wong TY. Diabetic retinopathy. Lancet. 2010; 376(9735):124-36.

28. Williamson TH, Shunmugam M, Rodrigues I, Dogramaci M, Lee E. Characteristics of rhegmatogenous retinal detachment and their relationship to visual outcome. Eye (Lond). 2013;27(9):1063-9.

29. Lv Z, Li Y, Wu Y, Qu Y. Surgical complications of primary rhegmatogenous retinal detachment: a meta-analysis. PLoS One. 2015;10(3):e0116493.

30. Suttorp-Schulten MS, Rothova A. The possible impact of uveitis in blindness: a literature survey. Br J Ophthalmol. 1996;80(9):844-8.

31. Tomkins-Netzer O, Talat L, Bar A, Lula A, Taylor SR, Joshi L, Lightman S Long-term clinical outcome and causes of vision loss in patients with uveitis. Ophthalmol. 2014;121(12):2387-92

32. Almasieh M, Wilson AM, Morquette B, Cueva Vargas JL, Di Polo A. The molecular basis of retinal ganglion cell death in glaucoma. Prog Retin Eye Res. 2012;31(2):152-81.

33. Lawlor M, Danesh-Meyer H, Levin LA, Davagnanam I, De Vita E, Plant GT. Glaucoma and the brain: trans-synaptic degeneration, structural change, and implications for neuroprotection. Surv Ophthalmol. 2018;63(3):296-306.

34. Weinreb RN, Aung T, Medeiros FA. The pathophysiology and treatment of glaucoma: a review. JAMA. 2014;311(18):1901-11.

35. Mabuchi F, Yoshimura K, Kashiwagi K, Shioe K, Yamagata Z, Kanba S, et al. High prevalence of anxiety and depression in patients with primary openangle glaucoma. J Glaucoma. 2008;17(7):552-7.

36. Jampel HD, Frick KD, Janz NK, Wren PA, Musch DC, Rimal R, et al. Depression and mood indicators in newly diagnosed glaucoma patients. Am J Ophthalmol. 2007;144(2):238-44.

37. Janz NK, Wren PA, Guire KE, Musch DC, Gillespie BW, Lichter PR. Fear of blindness in the collaborative initial Glaucoma treatment study: patterns and correlates over time. Ophthalmology. 2007:114(12):2213-20.

38. Stapleton F, Alves M, Bunya VY, Jalbert I, Lekhanont K, Malet F, et al. TFOS DEWS II epidemiology report. Ocul Surf. 2017;15(3):334-65.

39. Senra H, Macedo AF, Nunes N, Balaskas K, Aslam T, Costa E. Psychological and psychosocial interventions for depression and anxiety in patients with age-related macular degeneration: a systematic review. Am J Geriatr Psychiatry. 2019;27(8):755-73.

40. Maynard ML, Zele AJ, Kwan AS, Feigl B. Intrinsically photosensitive retina ganglion cell function, sleep efficiency and depression in advanced agerelated macular degeneration. Invest Ophthalmol Vis Sci. 2017;58(2):990-6.

41. Rynerson JM, Perry HD. DEBS - a unification theory for dry eye and blepharitis. Clin Ophthalmol. 2016:10:2455-67.

\section{Publisher's Note}

Springer Nature remains neutral with regard to jurisdictional claims in published maps and institutional affiliations.

Ready to submit your research? Choose BMC and benefit from:
- fast, convenient online submission
- thorough peer review by experienced researchers in your field
- rapid publication on acceptance
- support for research data, including large and complex data types
- gold Open Access which fosters wider collaboration and increased citations
- maximum visibility for your research: over 100M website views per year
At BMC, research is always in progress.
Learn more biomedcentral.com/submissions

